\title{
Branching and competitive hierarchies in populations of Galium aparine
}

\author{
Javier G. Puntieri and Petr Pyšek
}

\begin{abstract}
The role of branching on the development of size hierarchies was studied on experimental populations of the annual herb Galium aparine L. (Rubiaceae). All branches of plants growing at high and low density were severed as plants developed, and the growth of individual plants, the development of growth and size inequalities, and the mean change in the size ranking of plants over time were compared with those of populations of naturally branched plants. Size allometries were analysed for all treatments. The effect of the branch-severing treatment on growth and size inequalities was not significant for crowded populations. The position of individual plants in the ranking of weights in crowded conditions was less variable for populations of unbranched plants than for those of branched plants. Size and growth inequalities among branched plants were not significantly affected by population density. The hypothesis that branching increases the development of competitive hierarchies in G. aparine populations is not supported by the results. The role of height growth limitation in crowded conditions as a constraint to competitive hierarchy development is discussed.
\end{abstract}

Key words: allometry, branching pattern, competitive hierarchy, Galium aparine, intraspecific competition.

\begin{abstract}
Résumé : Les auteurs ont vérifié l'hypothèse proposant que la ramification encourage le développement de hiérarchies compétitives entre les plantes, au cours d'expériences sur des populations d'une herbacée annuelle, le Galium aparine L. (Rubiaceae). En cours de développement, ils ont excisé toutes les branches de plantes poussant sous de hautes et de basses densités et ils ont comparé, dans le temps, la croissance des plantes individuelles, le développement de la croissance, les inégalités de dimension et le changement moyen dans l'ordonnancement des dimensions des plantes, par rapport à des populations de plantes ayant conservé leurs ramifications naturelles. Ils ont analysé six allométries chez tous les traitements. L'effet du traitement d'élimination des ramifications sur la croissance et sur les inégalités de dimensions n'est pas significatif pour les populations denses. Dans les populations denses, la position de la plante individuelle dans l'ordonnancement selon le poids est moins variable pour les populations de plantes non-ramifiées que pour celles qui le sont. Les inégalités de dimension et de croissance parmi les plantes ramifiées ne sont pas significativement affectées par la densité de la population. Les résultats ne supportent pas l'hypothèse de départ. Les auteurs discutent le rôle de la limitation de croissance en hauteur dans les populations denses, comme contrainte au développement compétitif de la hiérarchie.
\end{abstract}

Mots clés : allométrie, patron de ramification, hiérarchie compétitive, Galium aparine, compétition intraspécifique. [Traduit par la rédaction]

\section{Introduction}

A hierarchy of resource exploitation, also referred to as competitive hierarchy or dominance-suppression relationship, is said to take place among crowded plants (Harper 1977, p. 160). Intraspecific plant-plant interactions usually increase size inequality among neighbours compared with that among noncompeting plants (e.g., Lomnicki 1988; Weiner and Thomas 1986; Weiner 1990). Although differences in seed size and emergence time are known to increase size inequalities (Stanton 1985; Miller 1987; Ellison and Rabinowitz 1989), growth inequalities caused by unequal resource capture are believed to play a key role in the development of size inequali-

Received March 4, 1997.

J.G. Puntieri. ${ }^{1}$ Department of Botany, Universidad Nacional del Comahue, Unidad Postal Universidad del Comahue,

Bariloche 8400, Argentina.

P. Pyšek. University of Agriculture Prague, Kostelec n.C.1., CZ - 28163 Czech Republic.

1 Author to whom all correspondence should be addressed. e-mail: jpuntier@uncmai.edu.ar ties among crowded plants (Weiner and Thomas 1986). The development of competitive hierarchies in crowded populations is also evidenced by size-related differences in plant shape and by a permanent position of neighbour plants on a size-ranking scale (Franco and Harper 1988; Geber 1989; Thomas and Weiner 1989; Tremmel and Bazzaz 1993, 1995; Weiner and Thomas 1992; Weiner and Fishman 1994; Aibo and Kohyama 1996). However, in some crowded plant populations, all neighbours have been found to be similarly suppressed by competition, so that size inequality does not increase with crowding and plant shape tends to be size independent (e.g., Oliver 1967; Newbery and Newman 1978; Rabinowitz 1979; Turner and Rabinowitz 1983; Ellison 1987; Brand and Magnussen 1988; Oliver and Larson 1990, p. 218; Stoll et al. 1994; Puntieri and Hall 1996).

Incident light shortage is considered to be the cause of competitive hierarchy development because of its unidirectionality and the increasing advantage it gives to larger over smaller plants (Hara 1988; Weiner and Thomas 1986; Weiner 1990). Branching allows plants to increase their light-capture area and shade casting over neighbour plants and, therefore, would accelerate competitive hierarchy development. The intrinsic pattern of growth and branching of a plant species has been 
Fig. 1. Illustrations of $G$. aparine plants at approximately $(a) 5$ days after emergence (the seedling has developed only an upright axis or main stem), (b) 10 days after emergence (basal branches are developing from the axillary buds of the cotyledons), and (c) 20 days after emergence (new branches are developing distally with respect to the basal branches). At stage 20 days, the plant needs some external physical support to grow upright.

\section{Early development of Galium aparine plants}

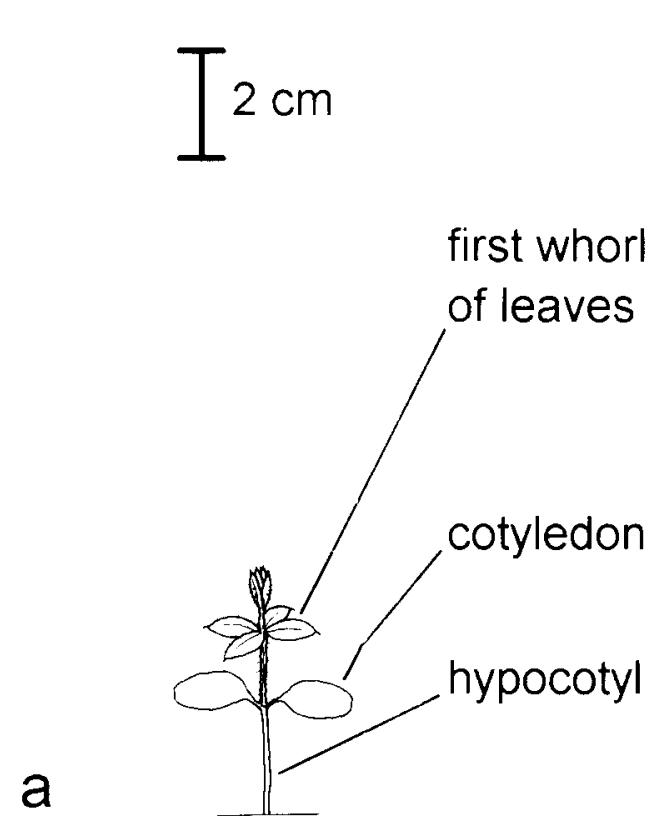

main stem

b

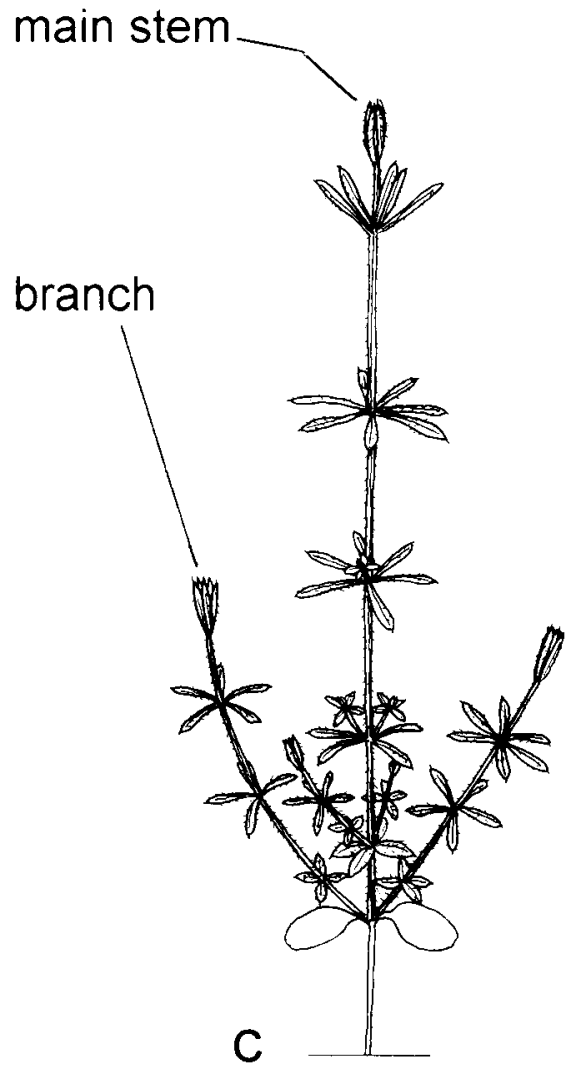

proposed as one of the factors affecting the development of competitive hierarchies (Weiner and Thomas 1986; Ellison 1989; Geber 1989; Schmitt and Wulff 1993; Room and Julien 1994). Under this view, a restriction of branching by crowding would limit competitive hierarchy development (Ellison 1989).

Galium aparine L. (Rubiaceae) plants develop an erect main stem with long, square-sectioned internodes separating whorls of elliptic to oblanceolate leaves. Plants are selfsupporting for some time after emergence; afterwards, they may keep growing upright if external support is available: the presence of hooked bristles on both stem and leaves of G. aparine plants allows them to climb without twining (Darwin 1891). If no external support is available, G. aparine plants may complete their life cycle as prostrated plants (Mamarot 1996). At high population density, G. aparine plants give physical support to one another, so that all may grow erect for weeks or even months (Puntieri and Pyšek 1993). We considered G. aparine to be a suitable subject for the study of competitive hierarchies for several reasons.

(1) The main stem in this species always derives from the seedling's apical meristem, and its early branching pattern is relatively homogeneous for the species: the first branches to develop, and also the most vigorous ones, derive from the cotyledons' axils and progressively smaller branches derive from more distal nodes along the main stem (Fig. 1). Throughout this text, the main axis of a plant is referred to as "main stem," whereas all other axes are referred to as "branches."

(2) The relatively large size of G. aparine seedlings makes branch removal practicable from very early stages of branch development (when a branch reaches about $2 \mathrm{~mm}$ long).

(3) The loss of branches, which occurs in natural conditions due to disturbance (J.G. Puntieri, personal observation), seems to have no detrimental effects on the growth of the main stem.

(4) Information about the behaviour of self-sown crowded populations of this species is available (Puntieri and Hall 1996).

Previous studies indicate that the development of size hierarchies is more delayed in $G$. aparine populations at high than at low population densities, particularly when physical support allows individuals to grow upright for a relatively long period (Puntieri 1993; Puntieri and Pyšek 1993). Delays in size hierarchy development have also been observed in roadside populations of this species with densities higher than 20000 plants $/ \mathrm{m}^{2}$ (Puntieri and Hall 1996). It has been argued in these studies that the restriction of branching at high population density would limit the development of competitive hierarchies.

In the present study the hypothesis that branching enhances the development of competitive hierarchies among crowded plants was tested. We compared the development of competi- 
tive hierarchies of populations of artificially unbranched plants with those of populations of naturally branched plants of $G$. aparine by means of a glasshouse experiment. Although studies centered on the response of crowded individual plants to a treatment, such as the present one, are highly demanding in terms of experimental surface and working effort, their contribution to our understanding of plant-plant interactions may be substantial (e.g., Franco and Harper 1988; Geber 1989).

\section{Materials and methods}

\section{Experimental design and measurements}

An experiment was carried out in a naturally lit glasshouse at Kostelec nad Cernými lesý (Czech Republic, 5000N, 14³0’E). It consisted of two population density treatments, high density (HD) and low density (LD), and two branching treatments, branched plants and unbranched plants. Galium aparine seeds were obtained from a seed supplier. The smallest seed size-classes $(<1 \mathrm{~mm}$ in diameter), more likely to be abortive (J.G. Puntieri, personal observations), were screened out. On 30 June 1993, seeds were sown in $13 \times 13 \times 15 \mathrm{~cm}$ plastic pots filled with a 50:50 mixture of sand and peat up to $2 \mathrm{~cm}$ from the top and were covered with $1 \mathrm{~cm}$ of the same soil. One hundred seeds were sown uniformly (visual estimation) in the HD pots, whereas 10 seeds were sown in the center of each LD pot, so as to make seed density similar in the pot centre for both densities.

On 19 July, 4 days after the emergence of most seedlings, all seedlings were at the stage of open cotyledons plus one to three, either developing or fully developed, whorls of normal leaves. By then, 10 plants within a $5 \mathrm{~cm}$ diameter circle in the center of each HD pot were labelled with coloured plastic rings; other plants growing within that circle were removed. The area around the labelled plants of each HD pot was occupied by 20-35 plants. In this respect, we gave priority to the homogeneity of the canopy of border plants over a constant density of plants in the border area. Population density in HD pots was equivalent to approximately 2000 plants $/ \mathrm{m}^{2}$. Only one plant was allowed to grow in each LD pot. All late-emerging seedlings were removed. Wooden stakes $(0.23 \times 30 \mathrm{~cm})$ were placed at the corners of each pot and a string was set around the top of the stakes connecting one another so as to provide plants with physical support. A second set of stakes and string was fixed on top of the first one when plant height exceeded $30 \mathrm{~cm}$. This allowed all plants to grow upright, even though some of them exceeded the supporting stakes in height. At high density, branches also developed vertically throughout the experiment. The longest branches of LD plants grew vertically in the first weeks after their initiation, but turned horizontal due to their own weight, so that growth beyond the pot's edges was unavoidable.

Each replicate consisted of one pot of each of the four treatments. Pots within a replicate were separated at least $25 \mathrm{~cm}$ from each other and their positions within the replicate were randomized daily. Twenty replicates were arranged in two parallel rows along a glasshouse bench. Pots belonging to contiguous replicates were at least $40 \mathrm{~cm}$ apart. All branches of labelled and border plants of the unbranched-treatment pots were severed daily during the experiment. Each branch was severed with small scissors, as close to the subtending main stem leaf as possible (each branch was $2-5 \mathrm{~mm}$ long when severed). Those branches on which flower buds could be distinguished (which developed from the top nodes of some plants in the last days of the experiment) were not severed. We considered that the contribution of such branches to the total light interception was minimal because of the small size of their leaves. Naturally branching plants were manipulated in the same way as those subjected to branch severing to minimize the importance of mechanical perturbation on the results (see Jaffe and Forbes 1993). Pots were watered daily. $\mathrm{N}-\mathrm{P}-\mathrm{K}$ fertilizer $\left(8.5 \% \mathrm{~N}, 8.5 \% \mathrm{P}_{2} \mathrm{O}_{5}, 12.0 \% \mathrm{~K}_{2} \mathrm{O}, 10 \mathrm{~g}\right.$ in $10 \mathrm{~L}$ of water) was provided to all pots once a week.

All labelled plants in HD pots and LD plants were non-destruc- tively measured 5 and 13 days after emergence with the object of estimating their individual dry weight (as detailed in the following section). On day 5, cotyledon length, main stem length (both to the nearest millimetre), and hypocotyl diameter (to the nearest $0.05 \mathrm{~mm}$ ) were recorded, whereas on day 13, main stem length, length of all branches, total length of the plant (i.e., main stem length + length of all branches), number of internodes of the main stem and diameter of the top whorl of leaves (to the nearest millimetre) were obtained. These size parameters, to be used as estimator variables, were selected on the basis of previous studies on this species (P. Pyšek and J.G. Puntieri, unpublished data).

All plants were harvested after 43 days of growth. Some plants were by then starting to produce their first flower buds, so that, essentially, vegetative growth had ceased. For each labelled plant, length, number of internodes, and maximum width of the main stem and hypocotyl diameter (the latter two measured with calipers to the nearest $0.1 \mathrm{~mm}$ ) were obtained. In the case of branched plants, the number of branches produced by the main stem, and the length and number of internodes of all branches were recorded. For each plant of the unbranched treatment, the number of branches initiated from axillary meristems was evaluated by means of counting the scars left by severed branches. The dry weight (to the nearest $0.1 \mathrm{mg}$ ) of main stem and branches was obtained for each labelled plant after drying for $48 \mathrm{~h}$ at $80^{\circ} \mathrm{C}$.

\section{Biomass estimation}

Pots were set up with $30-45$ (15 pots) or a single G. aparine plant (322 pots) to obtain equations for the estimation of the dry weight of labelled plants from non-destructive measurements. These pots were placed in parallel rows at least $40 \mathrm{~cm}$ from the experiment pots in the same glasshouse. In some of these plants, branches were severed as described above. All plants in some of these pots (3 HD pots and $131 \mathrm{LD}$ pots) were harvested on day 5 , and all plants in the remaining pots were harvested on day 13. For each recording day, the same measures as those obtained for the labelled plants were recorded and included as potential predictor variables. The removal of branches was included among the potential predictor variables of main stem weight ( 0 , no branches severed; 1 , all branches severed) for the second measurement, because of its possible influence on the relationship between dry weight and other dimensions. The predictor variables used in the estimation of the dry weight (either linear or log transformed) were incorporated in a forward-selection stepwise regression procedure (Sokal and Rohlf 1981). Nontendency of the residuals when plotted against the dependent variable was verified for the model with the highest $r^{2}$. Different equations were obtained for plants at high density and plants at low density for 5 and 13 days after emergence; in the latter case, main stem and branch weight were estimated separately.

\section{Data analysis}

Frequency distributions of plant weights were compared between branched and unbranched plants at 5, 13, and 43 days of growth by means of Kolmogorov-Smirnov two-sample $D$ tests (Sokal and Rohlf 1981).

The mean relative growth rate (RGR) of individual plants for the period $t_{1}-t_{2}$ was calculated using the following equation:

[1] $\mathrm{RGR}_{1-2}=\frac{\log W_{2}-\log W_{1}}{t_{2}-t_{1}}$

where $W_{1}$ and $W_{2}$ are aboveground dry weights (either estimated or measured) at times 1 and 2, respectively. Competitive hierarchy development at a given time was measured by means of: size inequality, growth inequality, and mean size ranking change. The coefficient of variation $(\mathrm{CV})$ of the mean dry weight was used as a measure of size inequality (as suggested in Weiner and Thomas (1986), Benjamin (1988), and Franco and Harper (1988)). The variance of the mean RGR was used as a measure of growth inequality. Since RGR vari- 
Table 1. Regression equations for the estimation of the aboveground dry weight $(\mathrm{W}, \mathrm{g})$ of $G$. aparine plants after 5 and 13 days of growth at two population densities.

\begin{tabular}{llrr}
\hline & & Least-squares regression equation & $r^{2}$ \\
\hline & \multicolumn{1}{c}{$\mathbf{5}$ days } & \\
Low density & $W=-0.00312+0.00122 \mathrm{SL}+0.00139 \mathrm{CL}+0.0673 \mathrm{BSD}$ & 0.895 & 131 \\
High density & $\log W=-6.89+0.134 \mathrm{SL}+0.663 \mathrm{CL}$ & 0.873 & 80 \\
& & $\mathbf{1 3}$ days & \\
Low density & & & 0.882 \\
Stem & $\log W=-4.90+0.130 \mathrm{SL}+0.0155 \mathrm{BL}+0.294 \mathrm{REMOVAL}$ & 191 \\
Branches & $W=-0.00324+0.00164 \mathrm{BL}$ & 130 \\
High density & & & 0.919 \\
Stem & $\log W=-6.08+0.0425 \mathrm{SL}+0.0222 \mathrm{LENGTH}+0.299 \mathrm{ITN}+0.227$ TOPDIAM $+0.192 \mathrm{REMOVAL}$ & 0.882 & 239 \\
Branches & $W=-0.000494+0.000887 \mathrm{BL}$ & 215 \\
\hline
\end{tabular}

Note: Regressor variables are as follows (only significant $(P<0.05)$ predictors are included): SL, stem length (= height, cm); CL, cotyledon length $(\mathrm{cm})$; BSD, basal diameter $(\mathrm{cm})$; BL, length of branches $(\mathrm{cm})$, REMOVAL, young branches removed (1) or not (0); LENGTH, total plant length (cm); ITN, number of internodes; TOPDIAM, diameter of the topmost leaf whorl $(\mathrm{cm})$. The coefficient of determination of each regression $\left(r^{2}\right)$ and the number of plants included in each case $(N)$ are indicated.

Fig. 2. Dry weight of high density $(a, c, e)$ and low density $(b, d, f) G$. aparine plants, $5(a, b), 13(c, d)$, and $43(e, f)$ days after emergence. Solid bars are branched plants, and open bars are unbranched plants.

\section{HIGH DENSITY}
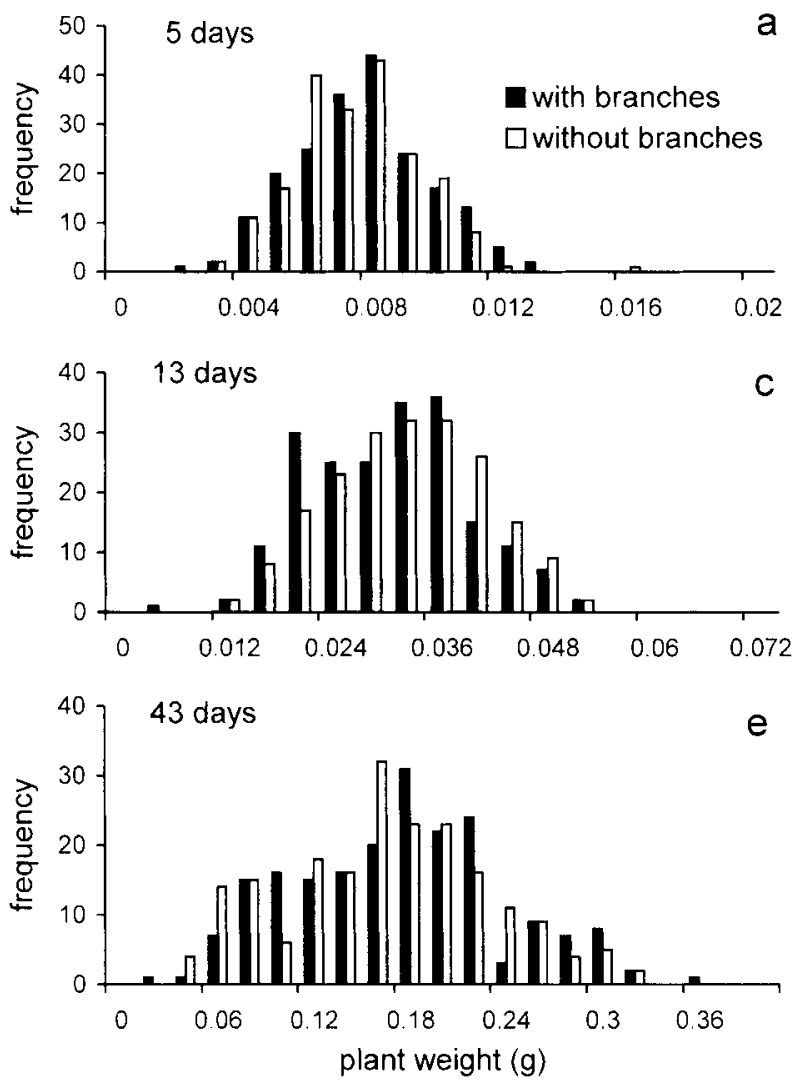

ance is responsible for differences in weight among plants (Koyama and Kira 1956), we took the variance of RGR as a predictor of future size inequality expected for a population. The mean size ranking change between two successive measurement days (1 and 2) was calculated by means of the equation:

[2] Mean size ranking change $=\frac{\sum_{i}\left(\left(\operatorname{rank}_{i 2}-\operatorname{rank}_{i 1}\right)^{2}\right)^{1 / 2}}{N}$
LOW DENSITY

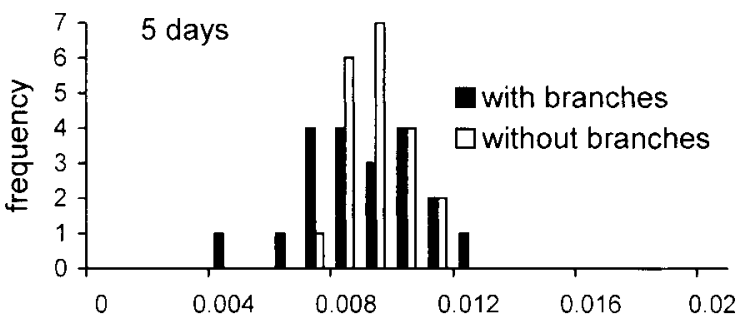

b
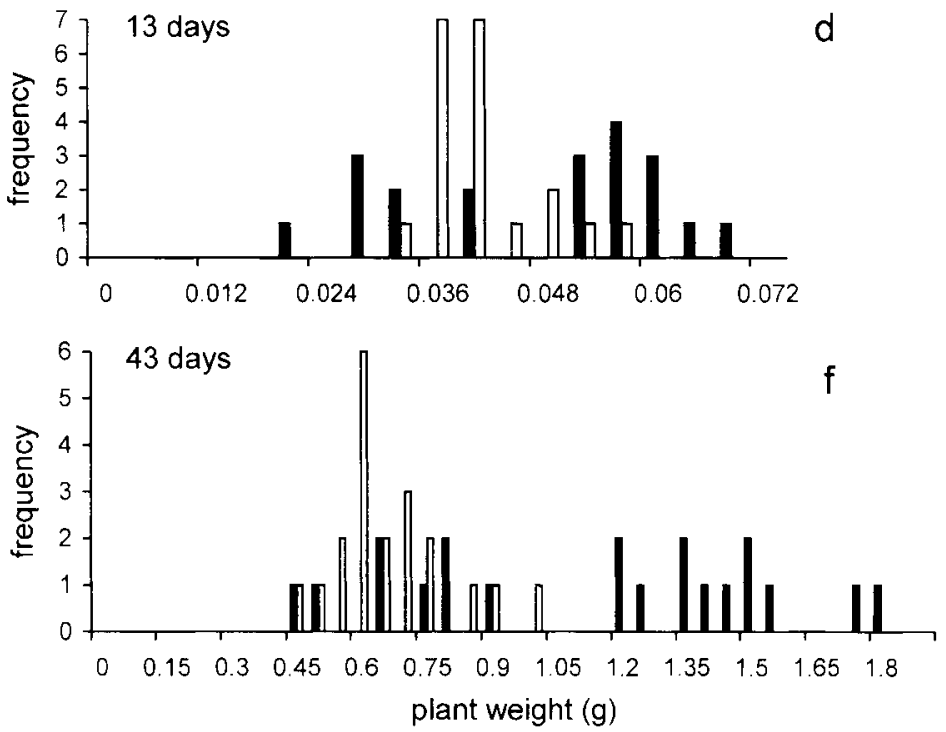

where $\operatorname{rank}_{i 1}$ and $\operatorname{rank}_{i 2}$ are the positions of plant $i$ in a ranking of dry weights at times 1 and 2, respectively, and $N$ is the number of plants for which mean ranking change was calculated.

For HD plants, size inequality, growth inequality, and mean size ranking change were calculated for the labelled plants of each pot, whereas in the case of LD plants, each variable was calculated for all pots of each treatment.

The effects of density and branching and their interaction on main 
Table 2. Mean \pm 1 SE of size measures of branched and unbranched Galium aparine plants at high and at low density after 43 days of growth.

\begin{tabular}{|c|c|c|c|c|c|c|c|}
\hline & \multicolumn{2}{|c|}{ High density } & \multicolumn{2}{|c|}{ Low density } & \multicolumn{3}{|c|}{$F$ test } \\
\hline & Branched & $\overline{\text { Unbranched }}$ & Branched & Unbranched & Density & Branching & Interaction \\
\hline Stem length $(\mathrm{cm})$ & $48.9 \pm 0.8$ & $48.1 \pm 1.1$ & $56.2 \pm 3.3$ & $57.2 \pm 1.9$ & $9.15^{* *}$ & $0.24 \mathrm{~ns}$ & $0.98 \mathrm{~ns}$ \\
\hline Stem weight (g) & $0.149 \pm 0.004$ & $0.155 \pm 0.005$ & $0.394 \pm 0.030$ & $0.645 \pm 0.030$ & $351.19 * * *$ & $17.93 * * *$ & $11.80 * * *$ \\
\hline Basal stem diameter (mm) & $0.71 \pm 0.01$ & $0.68 \pm 0.01$ & $0.81 \pm 0.02$ & $0.81 \pm 0.03$ & $37.26 * * *$ & $1.01 \mathrm{~ns}$ & $0.28 \mathrm{~ns}$ \\
\hline Maximum stem width (mm) & $1.03 \pm 0.01$ & $1.03 \pm 0.02$ & $1.78 \pm 0.07$ & $2.22 \pm 0.06$ & $434.95 * * *$ & $10.45 * *$ & $11.34 * * *$ \\
\hline
\end{tabular}

Note: The effects of density, branching, and their interaction assessed by means of row-wise two-way ANOVA on inverse square-root transformed data are given. $F$ test value is given with its significance. ${ }^{* * *}, P<0.001 ;{ }^{* *}, P<0.01 ;{ }^{*}, P<0.05$; ns, $P>0.05$ ).

stem length, number of internodes, maximum width, and dry weight and plant dry weight were assessed by means of two-way ANOVA on inverse square root transformed data. Normality and nontendency of residuals were graphically tested (Sokal and Rohlf 1981).

The log main stem weight ( $Y$ variable $)$ - log main stem length $(X$ variable) relationship was assessed for all plants of each treatment and the log plant weight - log plant length relationship (i.e., including main stem and branches) was assessed for HD and LD branched plants. The overall significance of the variation among regression slopes for each relationship was evaluated with Fisher's $F$ test. Tukey-Kramer tests for unplanned comparisons were carried out to compare pairs of regression slopes (Sokal and Rohlf 1981).

\section{Results}

\section{Biomass at 5 and 13 days}

In all biomass estimation equations, stem length was an important predictor variable (Table 1). At day 5, each plant consisted of an unbranched, erect main stem with up to three internodes, and cotyledon length contributed significantly to the estimation of plant biomass. For 13-day-old plants, the equation for main stem biomass estimation included, in addition to main stem length: the length of branches, the branch removal treatment and, for crowded plants, the number of main stem internodes and the diameter of the topmost leaf whorl.

The frequency distribution of estimated weights was similar between branched and unbranched HD plants after 5 and 13 days of growth $(D=0.08$ and $D=0.128$, respectively; $P>$ 0.05 ; Figs. $2 a$ and $2 c$ ). The distribution of dry weights at 5 days was similar for branched and unbranched LD plants $(D=0.25, P>0.05)$ but differed significantly at 13 days $(D=0.45, P<0.01)$ because of the higher dispersion for branched than for unbranched plants (Figs. $2 b$ and $2 d$ ).

\section{Plant development after $\mathbf{4 3}$ days}

The frequency distribution of dry weights after 43 days was similar for branched and unbranched HD plants $(D=0.09, P>$ 0.05 ) but differed notably between branched and unbranched LD plants $(D=0.55, P<0.001$; Figs. $2 e$ and $2 f)$.

Main stem length and internode number were significantly higher for LD than for HD plants, irrespective of the branching treatment (Figs. $3 a-3 d$, Table 2). Main stem weight was higher for unbranched than for branched plants at both densities (Figs. $3 e$ and $3 f$, Table 2). LD plants developed a notably heavier stem than HD plants (Table 2).

Hypocotyl diameter was significantly higher for LD than for HD plants but was unaffected by branching (Figs. $4 a$ and $4 b$, Table 2). The maximum stem width (which corre- sponded to one of the topmost internodes of each plant), was higher for LD than for HD plants; branch severing increased maximum stem width only in the case of LD plants (Figs. $4 c$ and $4 d$, Table 2).

The number of branches initiated from the main stem was proportional to plant weight for HD plants (Fig. 5). The linear regression between number of branches initiated on the main stem and plant weight had both a higher elevation $(F=142.9$, $P<0.001)$ and a higher slope $(F=408.5, P<0.001)$ for unbranched than for branched HD plants. In the case of LD plants, the number of branches initiated on the main stem was proportional to plant weight for branched plants but not for unbranched plants (Fig. 5). LD plants initiated a higher number of branches on the main stem than HD plants (Fig. 5).

\section{Relationship between size and RGR: size allometries}

The relationship between initial plant weight and RGR was not significant for any of the treatments either for the day 5-13 growth period or for the day 13-43 growth period $\left(0.05<r^{2}<\right.$ $0.179, P>0.05$ ).

The slope of the line relating log main stem weight and log main stem length after 43 days of growth differed significantly among treatments (Fig. $6 a$, Table 3; an unusually small plant of the branched HD treatment with a large standard residual and a large influence on that relationship was excluded from the analyses). Large individuals had a proportionally higher stem biomass per stem length unit than small individuals at HD than at LD. Branch severing did not affect that allometric relationship in the case of HD plants, whereas at LD, the stem biomass accumulated per unit of length was lower for unbranched plants than for branched plants (Fig. $6 a$, Table 3).

The addition of branches in the allometric weight-length relationship resulted in an inflexion in the case of HD plants: the line relating both variables for small plants (total weight $<0.11 \mathrm{~g}$ ) differed from that of large plants (Table 3 ). In the case of LD plants, the log total weight - log total length was linear (Fig. 6b). The ANOVA comparing all three lines indicated an overall significant difference in slope (Table 3), and paired comparisons showed that large plants at HD had a slope similar to that of LD plants, whereas the slope for small plants was steeper than those of large plants at HD and LD plants.

\section{Size and growth inequalities and ranking dynamics}

At $\mathrm{HD}$, the $\mathrm{CV}$ of the estimated weight per plant was not different between pots of branched and unbranched plants after 5 days of growth $(F=1.98, P=0.18)$ and was higher for 
Fig. 3. Frequency distributions of stem length $(a, b)$ and number of stem internodes $(c, d)$ of $G$. aparine plants after 43 days of growth at high density $(a, c)$ and at low density $(b, d)$ for 43 days. Solid bars are branched plants, and open bars are unbranched plants.

HIGH DENSITY
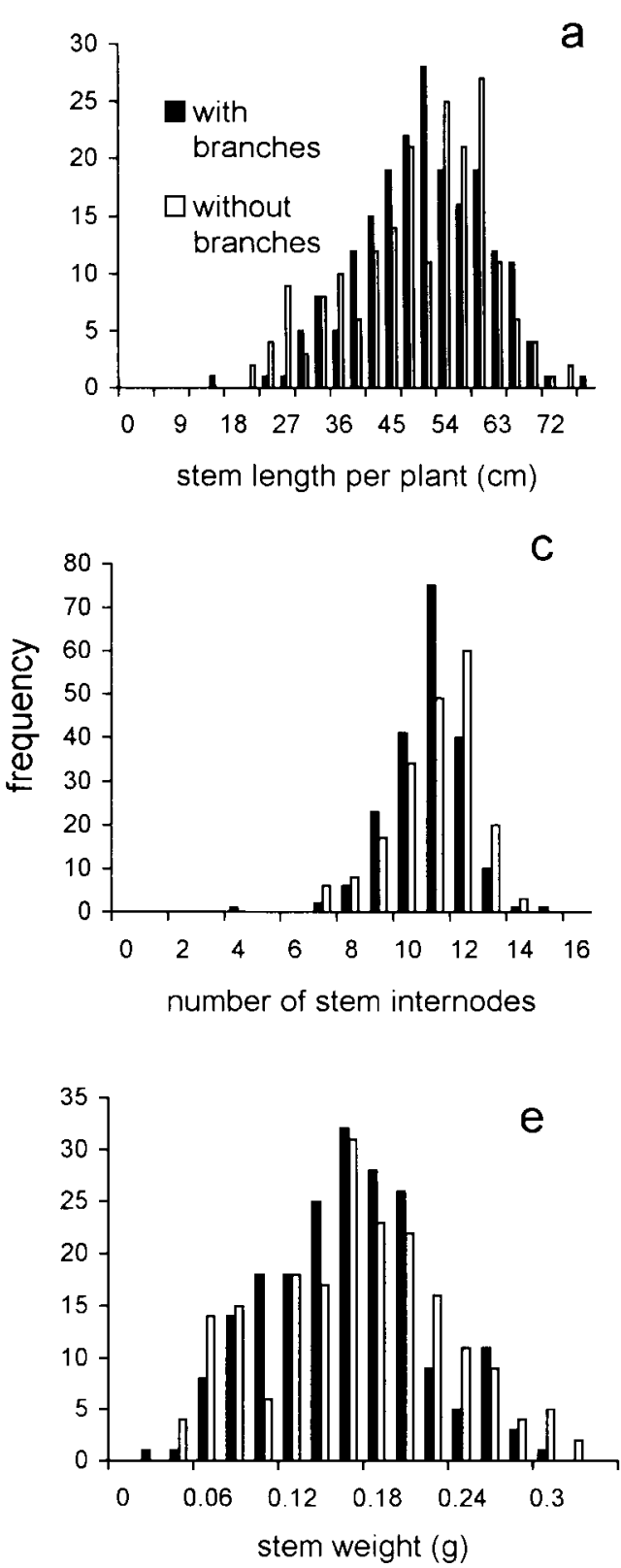

branched than for unbranched plants after 13 days $(F=7.17$, $P=0.015$, Fig. 7a). After 43 days of growth, the CV of the mean plant weight was similar between branched and unbranched HD plants $(F=0.65, P=0.43)$. The $\mathrm{CV}$ of the dry weight was consistently higher for branched than for unbranched LD plants (Fig. 7b). Among unbranched plants, significant differences were found between the $\mathrm{CV}$ of the mean plant weight of LD plants and the mean $\mathrm{CV}$ of HD plants for 5 $(t=2.21, P<0.05)$ and 43 days $(t=2.08, P<0.05)$ of growth but not for 13 days of growth $(t=1.19, P>0.05)$. In the case of branched plants, the $\mathrm{CV}$ of the mean weight of LD plants
LOW DENSITY
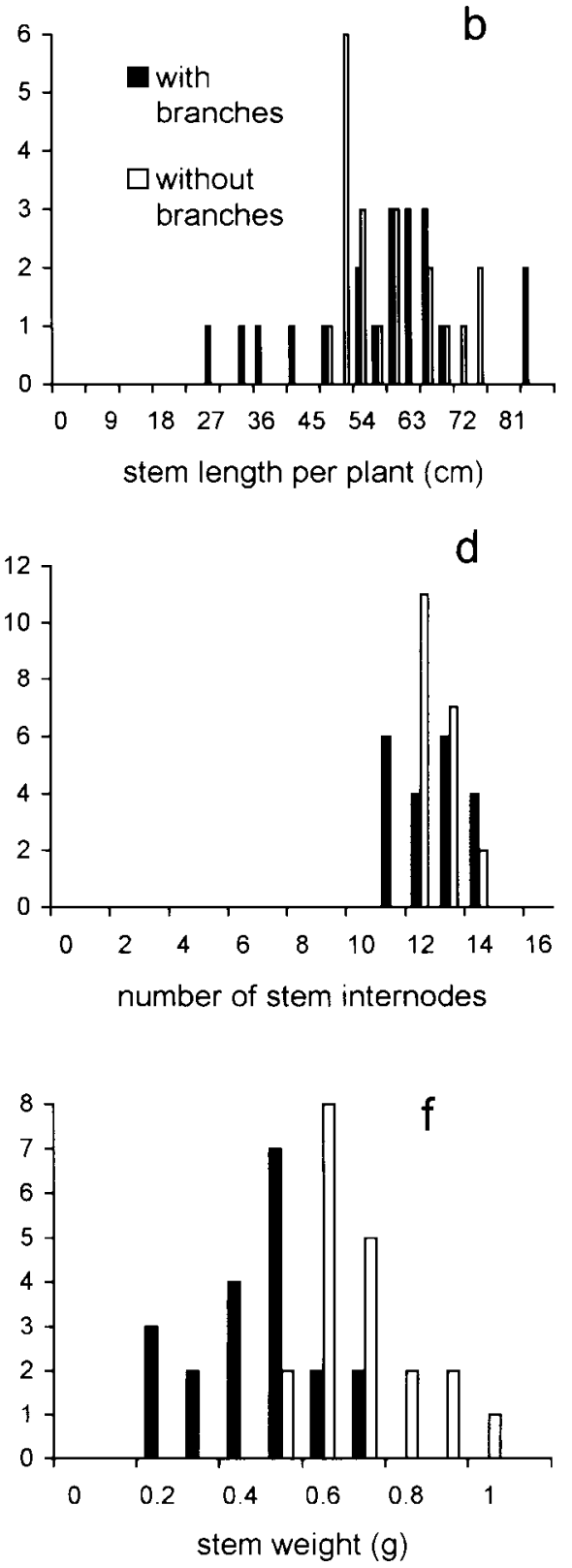

resembled the mean CV of HD plants for $5(t=0.11, P>0.05)$, $13(t=0.66, P>0.05)$, and 43 days $(t=0.05, P>0.05)$. For all four treatments, the $\mathrm{CV}$ of the mean plant weight increased over time.

The RGR variance did not differ between branched and unbranched HD plants either for the day $5-13$ period $(F=$ $0.70, P=0.41)$ or for the day $13-43$ period $(F=2.03, P=0.16$, Fig. $7 c$ ). The RGR variance for LD plants was not significantly different from the mean RGR variance of HD plants for both periods between measurements either in the case of branched plants $(t=0.25$ for the day $5-13$ period and $t=0.05$ for the 
Fig. 4. Frequency distributions of hypocotyl diameter $(a, b)$ and maximum stem width $(c, d)$ of $G$. aparine plants after 43 days of growth at high density $(a, c)$ and at low density $(b, d)$. Solid bars are branched plants, and open bars are unbranched plants.


Table 3. Slope of the equation relating log-main stem weight $(Y$ variable) and log-main stem length ( $X$ variable) for branched and unbranched plants at high density (HD) and at low density (LD), and slope of the equation relating log plant weight and log plant length (i.e., including main stem and branches) for large and small branched plants at HD and for branched plants at LD.

\begin{tabular}{lcrr}
\hline & Slope & $r^{2}$ & $N$ \\
\hline Stem weight $(\mathrm{g})-$ stem length $(\mathrm{cm}):$ & & & \\
$F=310.7^{* * *}$ & & & \\
HD branched & $1.567 a$ & 0.704 & 199 \\
HD unbranched & $1.556 a$ & 0.746 & 197 \\
LD branched & $1.488 b$ & 0.908 & 20 \\
LD unbranched & $1.177 c$ & 0.726 & 20 \\
Plant weight $(\mathrm{g})-$ plant length $(\mathrm{cm}):$ & & & \\
$F=96.1^{* * *}$ & & & \\
HD branched, large plants & $1.082 b$ & 0.741 & 151 \\
HD branched, small plants & $1.331 a$ & 0.689 & 48 \\
LD branched & $1.056 b$ & 0.761 & 20 \\
\hline
\end{tabular}

Note: The $F$ test value for the overall comparison among slopes is indicated for each of these relationships (***, $P<0.001$ ). For each $F$ test, slopes followed by the same letter are not significantly different at $P<0.05$ (a posteriori Tukey-Kramer paired comparisons). The coefficient of determination $\left(r^{2}\right)$ for each regression equation and the number of plants $(N)$ on which each regression was based are given.

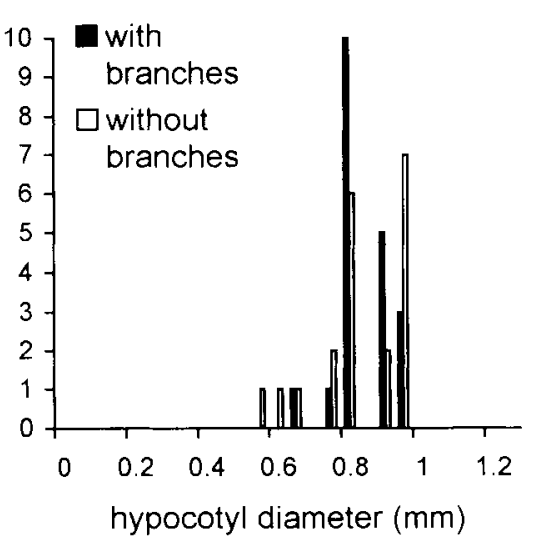

d

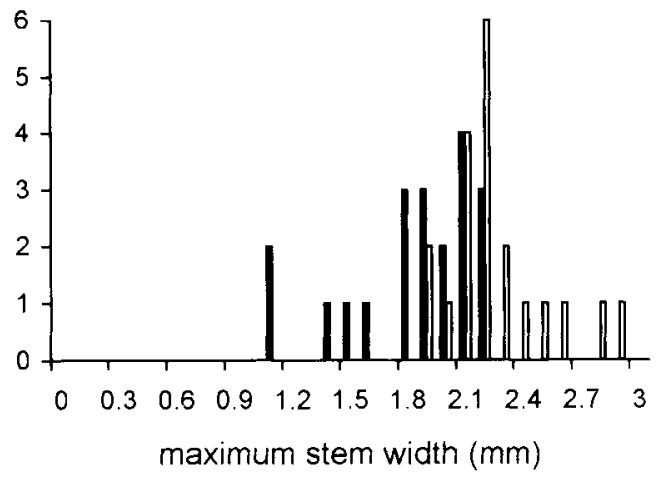

day 13-43 period, $P>0.1$ ) or in the case of unbranched plants ( $t=0.70$ for the day $5-13$ period and $t=1.58$ for the day $13-43$ period, $P>0.05$; Figs. $7 c$ and $7 d$ ).

The mean change in the ranking of dry weights was similar for branched and unbranched HD plants for the day 5-13 period $(F=0.01, P=0.91$, Fig. $7 e)$, but it was significantly higher for branched plants than for unbranched plants for the day $13-43$ period $(F=10.4, P<0.01)$. The mean ranking change of LD plants was not significantly different from the mean for HD plants in the case of branched plants $(t=1.75$ for the day 5-13 period and $t=76$ for the day $13-43$ period, $P>$ $0.05)$, but it was significantly higher than the mean found for HD plants in the case of unbranched plants $(t=2.65$ for the day 5-13 period, $P<0.05$, and $t=5.56$ for the day 13-43 period, $P<0.001$; Figs. $7 e$ and $7 f$ ).

\section{Discussion}

\section{Effects of crowding and branch severing on the growth of $G$. aparine}

In the present study, crowding of $G$. aparine plants reduced main stem biomass mostly by affecting main stem width; main stem length and internode number were far less relevant to main stem biomass (Table 2). The effect of the branch- 
Fig. 5. Relationship between number of branches initiated on the main stem and plant weight for high-density (circles) and low-density (squares) plants. Solid symbols are branched plants, and open symbols are unbranched plants.

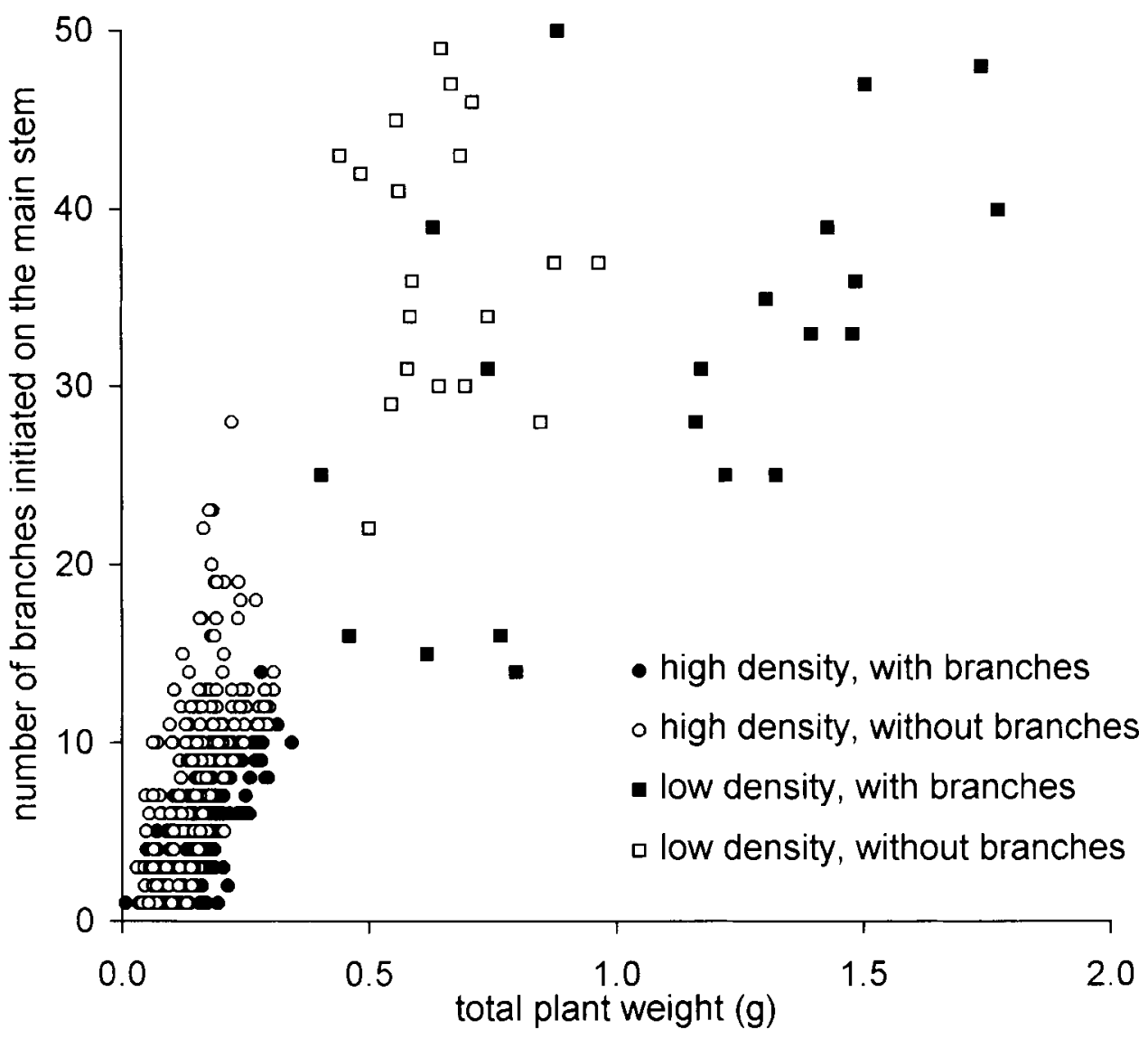

severing treatment applied here on main stem growth was far more notable for LD than for HD plants.

HD plants in which branching was allowed either remained unbranched (the smallest individuals) or developed a low number of branches compared with branched LD plants (Fig. 5). The similar log weight - log length relationship found for the main stem of HD and LD branched plants (Fig. 6a, Table 3) indicates that the difference in stem shape between large and small individuals was similar at both densities. The inclusion of branches in this allometric relationship altered this pattern: large individuals at HD still followed a log weight log length relationship similar to that of LD plants, whereas small individuals at HD increased proportionally more in biomass than in length than either large HD plants or LD plants (Fig. 6b, Table 3). This could be due to the fact that branches, which represent a more important fraction of plant biomass and length in large HD plants and LD plants than in small HD plants, have an elongation pattern that differs from that of the main stem.

Branch severing of HD plants stimulated the initiation of new branches from axillary positions on the main stem, more notably so for large than for small plants. Nevertheless, the weight-length allometry of the main stem was unaffected by the branch-severing treatment in HD plants. At LD, on the contrary, the initiation of new branches was not increased by the branch-severing treatment, but the stem allometry was largely affected. Interestingly, LD plants responded to branch severing by developing thicker main stem internodes, but HD plants did not. This indicates that the process of branching does not represent, in itself, a hindrance to main stem width growth at HD in G. aparine. Kemball et al. (1992) suggested that, in G. aparine, main stem and branches might act as competing sinks for resources taken up by the roots. On the basis of the present results, it could be hypothesized that the degree of competition for resources between main stem and branches in this species would decrease with population density.

\section{Competitive hierarchies in $G$. aparine populations}

Among those parameters utilized here to assess the development of competitive hierarchies, the most typically used ones, i.e., size inequality, RGR variance, and the relationship between RGR and plant size (Weiner and Thomas 1986; Weiner 1990), indicate that crowding did not accelerate the development of competitive hierarchies among naturally branched plants. The similarity between HD and LD branched plants with respect to the mean change in the ranking of sizes complies with these results (Fig. 7).

The development of branches is considered an important component in the development of competitive hierarchies among plants (Weiner and Thomas 1986; Ellison 1989; Geber 1989; Schmitt and Wulff 1993; Room and Julien 1994). Under this perspective, the prevention of branching should have a 
Fig. 6. Relationships between (a) main stem length and main stem dry weight (log-log scale) and (b) plant length and plant dry weight (including main stem and branches) (log-log scale) for branched (solid symbols) and unbranched (open symbols) plants at high density (circles) and at low density (squares). The slope of the linear equation corresponding to each relationship and the results of slope comparisons are shown in Table 3. The solid circle on the left-bottom corner of each graph was considered an outlier and was excluded from the comparisons.
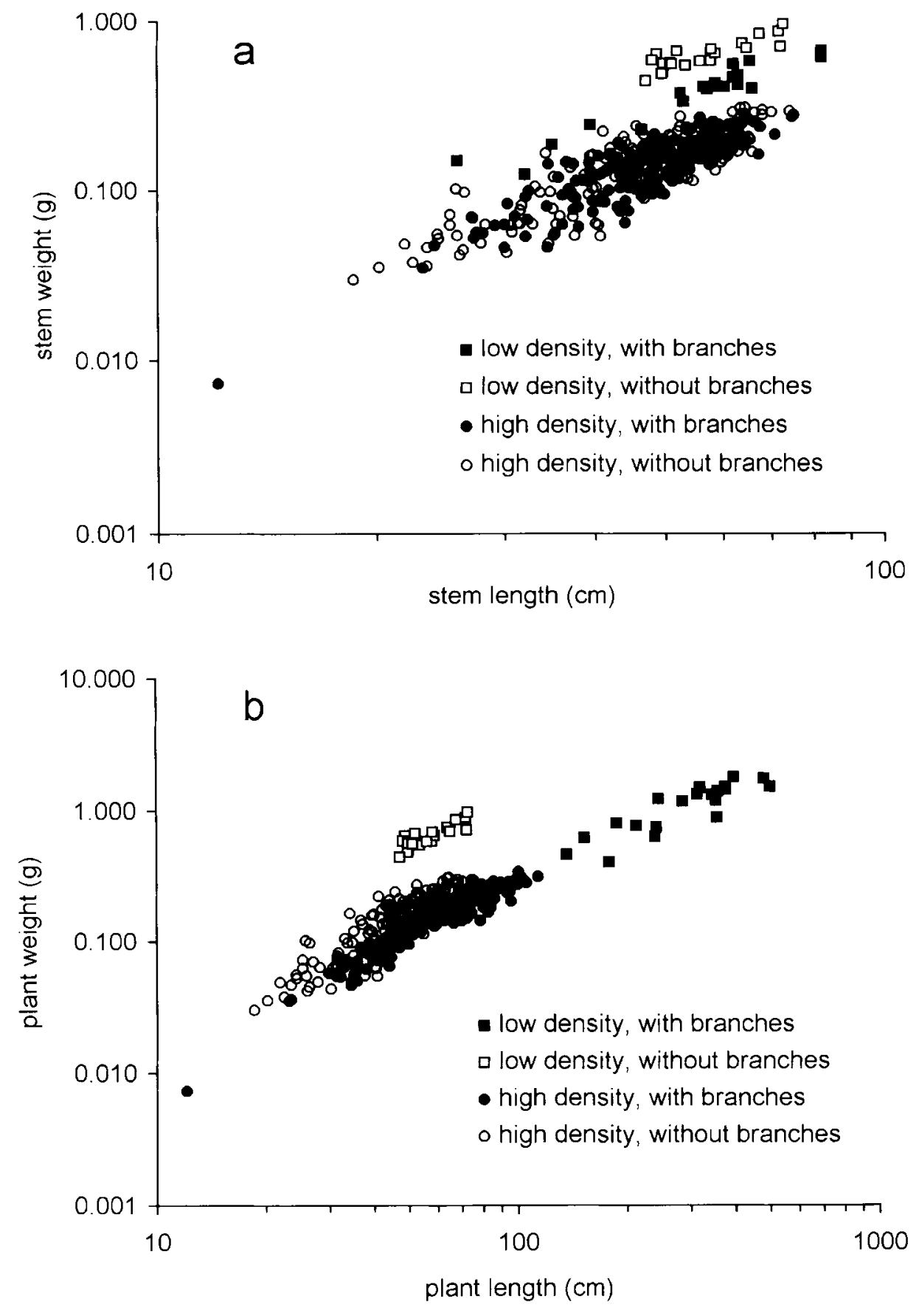

negative effect on the development of competitive hierarchies. However, in the present study there were no clearcut differences between branched and unbranched HD plants with respect to either size inequality or growth inequality (Fig. 7), and their size distributions were similar to each other (Fig. 2).
Moreover, the ranking of sizes of unbranched plants at HD was less variable than that of branched plants at HD for the day 13-43 period (Fig. 7e). This suggests that, although branch severing resulted in a more stable ranking of plants on a size scale, the largest individuals in that treatment could not 
Fig. 7. Coefficient of variation (CV) of plant dry weight after 5, 13, and 43 days of growth $(a, b)$ and relative growth rate (RGR) variance ( $c$, $d)$ and mean size ranking change $(e, f)$ for the periods between 5 and 13 days and between 13 and 43 days of growth. In the case of high-density plants $(a, c, e)$, the mean $+1 \mathrm{SE}$ of the values calculated for each pot are indicated. In the case of low-density plants $(b, d, f)$, each value represents 20 plants. Solid bars are branched plants, and open bars are unbranched plants.

HIGH DENSITY

a

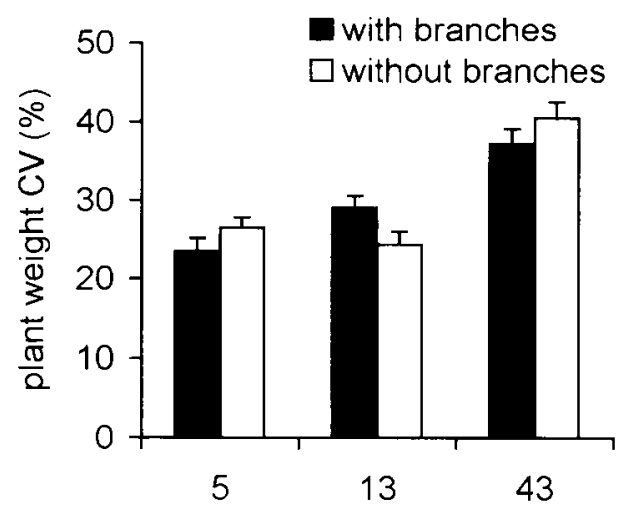

days from emergence
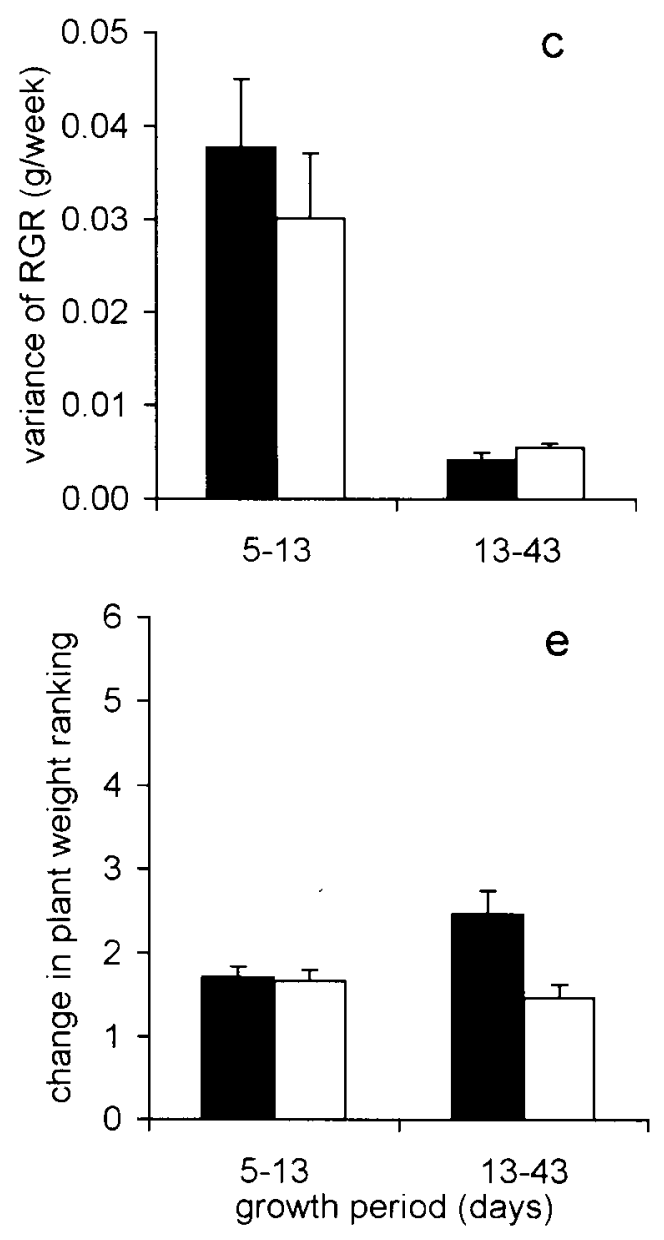

LOW DENSITY
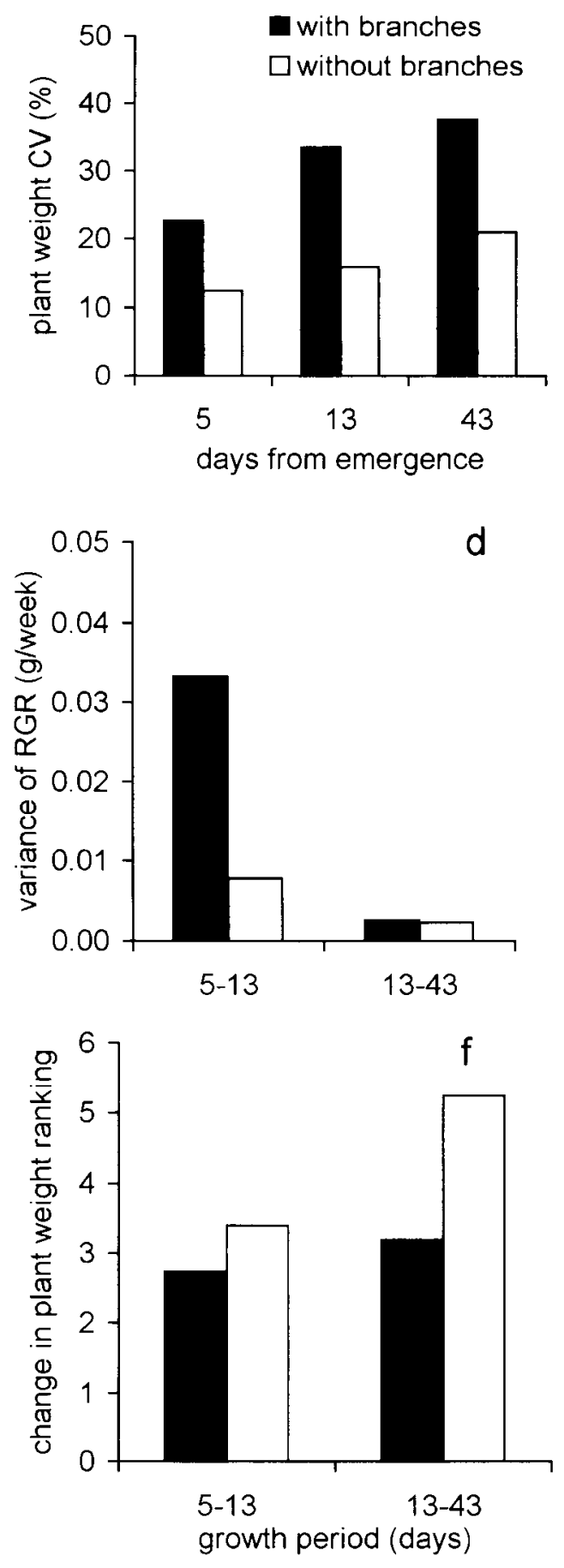
profit from their advantageous position in that ranking, so that size inequality among unbranched plants did not increase relative to that among branched plants.

Competition for light is likely to have been an important selective force favouring height growth (Givnish 1982; King 1990; González Ponce et al. 1996). Differences in height are believed to play a key role in the development of competitive hierarchies among plants (Franco and Harper 1988; Weiner 1990). An increase in height growth at the expense of branching (sometimes termed apical dominance) is a common response of plants to crowding (Geber 1989, and references therein). In the case of $G$. aparine, crowding seems to have the opposite effect, tending to reduce both the average and the variation in height growth (i.e., main stem length) among neighbours. In addition, branching does not increase size inequalities among crowded plants, because of their low accumulation of biomass in branches. Furthermore, the capacity of $G$. aparine plants to attach to one another with their hooked bristles allows crowded plants of all sizes to grow upright despite the biomechanically unstable stem shape (with increasing diameter towards its apex; see Givnish 1995). This prevents the lodging of some individuals, which may increase height differences among neighbours and, as a result, size inequality (Thomas and Weiner 1989).

Previous studies have suggested that the absence of competitive hierarchy development in some crowded populations of plants is typical of plant species in which branching is limited and shade casting by leaves is inherently low, as in grasses and small-leafed or leafless species (Turner and Rabinowitz 1983; Ellison 1989; Ellison and Rabinowitz 1989; Geber 1989). In view of the present results, it could be suggested, alternatively, that the development of competitive hierarchies would be restricted whenever plant-plant interactions prevent height differences among neighbours to increase. This would depend on how the expression of a species' developmental rules is affected by the presence of neighbour plants. The tendency of crowded populations of some plant species not to develop an early competitive hierarchy would have important implications in the case of weeds of cultivated lands. Population density of a weed species is considered to be positively related to crop yield loss (Cousens 1985; Lutman et al. 1996). If interacting plants of a weed suppress each other during early growth rather than establish a dominance-suppression relationship, their future competitive effect on the crop as well as their potential seed production and eventual dispersal would decline with population density.

\section{Acknowledgements}

We thank T. Herben, J. Chiapella, E. Raffaele, D. Barthélémy, M. Oesterheld, M. Aizen, and J. Weiner for useful comments on previous versions of the manuscript; N. Baccalá for statistical advice; and P. Artner and P. Skrivan for logistic support. This study was made possible thanks to the interest of the Institute of Applied Ecology, University of Agriculture, Prague (Czech Republic), and the Universidad Nacional del Comahue (Argentina).

\section{References}

Aibo, S.-I., and Kohyama, T. 1996. Tree species stratification in rela- tion to allometry and demography in a warm-temperate rain forest. J. Ecol. 84: 207-218.

Benjamin, L.R. 1988. A single equation to quantify the hierarchy in plant size induced by competition within monocultures. Ann. Bot. (London), 62: 199-214.

Brand, D.G., and Magnussen, S. 1988. Asymmetric, two-sided competition in even-aged monocultures of red pine. Can. J. For. Res. 18: 901-910.

Cousens, R.D. 1985. A simple model relating yield loss to weed density. Ann. Appl. Biol. 107: 239-252.

Darwin, C. 1891. The movements and habits of climbing plants. John Murray, London, U.K.

Ellison, A.M. 1987. Density-dependent dynamics of Salicornia europaea monocultures. Ecology, 68: 737-741.

Ellison, A.M. 1989. Morphological determinants of self-thinning in plant monocultures and a proposal concerning the role of selfthinning in plant evolution. Oikos, 54: 287-293.

Ellison, A.M., and Rabinowitz, D. 1989. Effects of plant morphology and emergence time on size hierarchy formation in experimental populations of two varieties of cultivated peas (Pisum sativum). Am. J. Bot. 76: 427-436.

Franco, M., and Harper, J.L. 1988. Competition and the formation of spatial pattern in spacing gradients: an example using Kochia scoparia. J. Ecol. 76: 959-974.

Geber, M. 1989. Interplay of morphology and development on size inequality: a Polygonum greenhouse experiment. Ecol. Monogr. 59: $267-288$.

Givnish, T.J. 1982. On the adaptive significance of leaf height in forest herbs. Am. Nat. 120: 353-381.

Givnish, T.J. 1995. Plant stems: biomechanical adaptation for energy capture and influence on species distributions. In Plant stems: physiology and functional morphology. Edited by B.L. Gartner. Academic Press, San Diego, Calif. pp. 3-49.

González Ponce, R., Zancada, C., Verdugo, M., and Salas, L. 1996. Plant height as a factor in competition between black nightshade and two horticultural crops (tomato and pepper). J. Hortic. Sci. 71: $453-460$

Hara, T. 1988. Dynamics of size structure in plant populations. Trends Ecol. Evol. 3: 129-133.

Harper, J.L. 1977. Population biology of plants. Academic Press, London, U.K.

Jaffe, M.J., and Forbes, S. 1993. Thigmomorphogenesis: the effects of mechanical perturbation on plants. Plant Growth Regul. 12: $313-324$.

Kemball, W.D., Palmer, M.J., and Marshall, C. 1992. The effect of local shading and darkening on branch growth, development and survival in Trifolium repens and Galium aparine. Oikos, 63: $366-375$.

King, D.A. 1990. The adaptive significance of tree height. Am. Nat. 135: 809-828.

Koyama, H., and Kira, T. 1956. Intraspecific competition among higher plants. VII. Frequency distribution of individual plant weight as affected by the interaction between plants. J. Inst. Polytech. Osaka City Univ. Ser. D, 7: 73-94.

Lomnicki, A. 1988. Population ecology of individuals. Monogr. Popul. Ecol. No. 25. Princeton University Press, Princeton, N.J.

Lutman, P.J., Risiott, R., and Osterman, H.P. 1996. Investigations into alternative methods to predict the competitive effects of weeds on crop yields. Weed Sci. 44: 290-297.

Mamarot, J. 1996. Mauvaises herbes des cultures. Association de Coordination Technique Agricole. Le Carrousel, Paris, France.

Miller, T.E. 1987. Effects of emergence time on survival and growth in an old-field plant community. Oecologia, 72: 272-278.

Newbery, D.M., and Newman, E.I. 1978. Competition of different grassland species of different initial sizes. Oecologia, 33: 361-380.

Oliver, C.D., and Larson, B.C. 1990. Forest stand dynamics. McGraw-Hill Inc, New York. 
Oliver, W.W. 1967 Ponderosa pine can stagnate on a good site. J. For. 65: 814-816.

Puntieri, J.G. 1993. Population density and size inequality in Galium aparine. Preslia, 65: 53-62.

Puntieri, J.G., and Hall, R.L. 1996. Density-dependent mortality, growth and size inequality in roadside populations of the annual herb Galium aparine L. Ecol. Res. 11: 121-137.

Puntieri, J.G., and Pyšek, P. 1993. The effects of physical support and density on biomass production and size hierarchies of Galium aparine populations. Oikos, 66: 279-284.

Rabinowitz, D. 1979. Bimodal distribution of seedling weight in relation to density of Festuca paradoxa Desv. Nature (London), 277: 297-298.

Room, P.M., and Julien, M.H. 1994. Population-biomass dynamics and the absence of $-3 / 2$ self-thinning in the clonal weed Salvinia molesta. Aust. J. Ecol. 19:26-34.

Schmitt, J., and Wulff, R.D. 1993. Light spectral quality, phytochrome and plant competition. Trends Ecol. Evol. 8: 47-51.

Sokal, R.P., and Rohlf, F.J. 1981. Biometry. W.H. Freeman, San Francisco, Calif.

Stanton, M. 1985. Seed size and emergence time within a stand of wild radish (Raphanus raphanistrum L.): the establishment of a fitness hierarchy. Oecologia, 67: 524-531.
Stoll, P., Weiner, J., and Schmid, B. 1994. Growth variation in a naturally established population of Pinus sylvestris. Ecology, 75: $660-670$.

Thomas, S.C., and Weiner, J. 1989. Growth, death and size distribution change in an Impatiens pallida population. J. Ecol. 77: $524-536$.

Tremmel, D.C., and Bazzaz, F.A. 1993. How neighbor canopy architecture affects target performance. Ecology, 74: 2114-2124.

Tremmel, D.C., and Bazzaz, F.A. 1995. Plant architecture and allotion in different neighborhoods: implications for competitive success. Ecology, 76: 262-271.

Turner, M.D., and Rabinowitz, D. 1983. Factors affecting frequency distributions of plant mass: the absence of dominance and suppression in competing monocultures of Festuca paradoxa. Ecology, 64: 469-475.

Weiner, J. 1990. Asymmetric competition in plant populations. Trends Ecol. Evol. 5: 360-364.

Weiner, J., and Fishman, L. 1994. Competition and allometry in Kochia scoparia. Ann. Bot. (London), 73: 263-271.

Weiner, J., and Thomas, S.C. 1986. Size variability and competition in plant monocultures. Oikos, 47: 211-222.

Weiner, J., and Thomas, S.C. 1992. Competition and allometry in three species of annual plants. Ecology, 73: 648-656. 